University of Rhode Island

DigitalCommons@URI

Open Access Master's Theses

1992

\title{
Moral Reasoning Related to Gender and Dilemma Content
}

Lisa Rocchio Giordano

University of Rhode Island

Follow this and additional works at: https://digitalcommons.uri.edu/theses

\section{Recommended Citation}

Giordano, Lisa Rocchio, "Moral Reasoning Related to Gender and Dilemma Content" (1992). Open Access Master's Theses. Paper 1645.

https://digitalcommons.uri.edu/theses/1645

This Thesis is brought to you for free and open access by DigitalCommons@URI. It has been accepted for inclusion in Open Access Master's Theses by an authorized administrator of DigitalCommons@URI. For more information, please contact digitalcommons-group@uri.edu. 


$$
\begin{aligned}
& B F 692.2 \\
& 6567 \\
& 1992
\end{aligned}
$$

MORAL REASONING RELATED TO GENDER AND DILEMMA CONTENT

BY

IISA ROCCHIO GIORDANO

A THESIS SUBMITTED IN PARTIAL FULFILLMENT OF THE REQUIREMENTS FOR THE DEGREE OF MASTER OF ARTS

IN

PSYCHOLOGY

$$
27052021
$$

UNIVERSITY OF RHODE ISLAND 


\section{Abstract}

Women's and men's use of care and justice considerations in response to moral dilemmas was investigated. Participants were 63 men and 127 women ranging in age from 17 to 64. Each was presented with one of two dilemmas dealing with either abortion or drug use, as it affected either a daughter or a son, and asked to respond to the dilemma both in an open-ended format and in a Likert scale format. A Chi Square analysis was used to analyze the essay responses, which were categorized as primarily justice, primarily care, or both. The content of the dilemma was found to have a significant impact on the distribution of the responses $(\underline{p}<.01)$. There were more justice considerations and fewer care considerations than expected by chance in response to the abortion dilemma, and more care responses and fewer justice responses than expected by chance in response to the drug dilemma. There was no effect for gender of either the respondent or the protagonist in the dilemma. Analysis of variance, used to analyze the Likert responses, revealed no effect for gender of the participant or gender of the protagonist, but those respondents who had a dilemma dealing with abortion used justice considerations significantly more often than did those whose dilemma dealt with drug use ( $p<.05)$. These findings are discussed in relation to the significance of abortion for Rhode Island residents. 


\section{ACKNOWLEDGEMENTS}

First, I would like to thank my major professor, Dr. Bernice Lott for her support, energy, and inspiration. I am truly grateful for her commitment to her students, and for her friendship and mentorship. I would also like to thank the rest of my committee, Drs. Allan Berman and Barbara Luebke, and the chair of my committee, Dr. Lynn Pasquerella, for their insightful and valuable contributions to this project. Aly Andrews, thank you for coding all of the data, and thanks to Drs. Katherine Quina and Lawrence Grebstein for providing me with access to student participants. Thank you to all who participated; without you, this research would not have been possible.

Thank you also to my parents for their constant love and support, and for instilling in me the self confidence to embark on a career in psychology. My brother Anthony, thank you; your talent and creativity have always been an inspiration to me. Finally, and most of all, thank you vincent for your endless love, enthusiasm, nurturance, and comfort. 


\section{Table of Contents}

Page

Abstract

ii

Acknowledgements

iii

Table of Contents

iv

List of Tables

v

Introduction

1

Method

Results

Discussion

Appendix

Bibliography 


\section{LIST OF TABLES}

Page

1. Participants' Mean Ages and Gender 14

2. Observed and Expected Frequencies of Care, 21 Justice, and Care/Justice Responses by Women and Men

3. Observed and Expected Frequencies of Care, Justice, and Care/Justice Responses to a Dilemma Dealing With Abortion or Drug Use

4. Observed and Expected Frequencies of Care, Justice, and Care/Justice Responses for Dilemmas Involving Daughters or Sons

5. Women's and Men's Mean Care Scores for an Abortion and Drug Dilemma Involving Daughters or Sons

6. Women's and Men's Mean Justice Scores for an 25 Abortion and Drug Dilemma Involving Daughters or Sons 
Moral Reasoning Related to

Gender and Dilemma Content

The intent of this research was to investigate the patterns of reasoning by women and men, and the role of dilemma content, in the use of justice and care orientations in response to moral dilemmas.

Carol Gilligan (1977, 1982a), whose work has focused on gender differences in moral reasoning, has criticized other theories of moral development, most notably Kohlberg's, for bias against women, as well as for the use of hypothetical moral dilemmas. She has pointed out that Kohlberg's stage theory, as well as that of his predecessor, Piaget, was developed by studying only boys and men; no girls or women were included in their original research samples. Because of the exclusion of women and girls, Gilligan concluded that "developmental theory has not given adequate expression to the concerns and experience of women" (1977, p. 481). Gilligan argued that Kohlberg's theory, based on a morality of justice and rights, does not adequately capture women's experience, resulting in women frequently being scored at a stage below that of men.

The observation that women tend to be scored lower than men, made both by Gilligan (1977, 1982a) and Kohlberg (1971), has since been addressed in a new scoring manual (Colby \& Kohlberg, 1987). When the educational level and social class of women is controlled for, gender differences in stage level 
are no longer found. Walker (1986), in an extensive review of empirical studies of gender differences in Kohlberg's stages, found that there really were no significant differences. Further, he found that the few studies that did find significant gender differences did not control for the educational level of their samples, and that the majority tended to use older versions of the scoring manual. While Walker's method of analysis was criticized by Baumrind (1986), his rejoinder (1986) addresses and refutes her concerns. When he recalculated his meta analysis utilizing her suggested statistic, he still found no evidence of an overall gender difference in stage level of moral reasoning using Kohlberg's schema.

Gilligan has continued to focus on gender differences in her discussion of the inherent bias in Kohlberg's work (1977, 1982a). After interviewing 29 pregnant women who were contemplating abortion, Gilligan and Belenky (1980) proposed that women proceed along a different, but equally valuable, path of moral development than do men. At the first level, women are said to be preoccupied with themselves and survival, viewing morality as simply obeying societal laws and restrictions. They then are said to proceed through a transitional phase from selfishness to responsibility. At this time, it is proposed that women become aware of the differences between what they want to do and what they feel they should do; their views become less egocentric. At this 
second level, women are said to move to a sense of responsibility, equate goodness with self-sacrifice and caring for others, and become preoccupied with what others want or expect, excluding their own values and concerns from the decision making process. At the second transitional level, women are said to be again concerned with their own needs, and recognize in themselves a sense of inner judgment. At the third and highest level, women are said to be able to both assert their own individual rights and to give equal consideration to their responsibility to others. The main principle at this level is that of non-violence; the primary motive is to avoid hurt and to sustain relationships while still preserving personal values and rights.

Gilligan has labeled the above process of moral development a morality of care, and that described by Kohlberg as a morality of justice. She views the morality of care as characteristic of the feminine voice and the moral imperative for women an "injunction to care". In contrast, in the morality of justice, the moral imperative is an "injunction to respect the rights of others and thus to protect from interference the right to life and self-fulfillment" (1977, p. 511)

Gilligan has further claimed that the hypothetical dilemmas Kohlberg uses are useful for demonstrating objective principles of justice, but are inadequate for demonstrating the contextual principles of care and connectedness embedded 
in women's thinking. She justifies talking to women contemplating abortion on the grounds that consideration of an abortion is a situation that places a woman in conflict with the cultural definition of femininity, and elicits concerns of selfishness and responsibility. She claims there exist "two different moral languages, the language of rights that protects separation and the language of responsibility that sustains connection" (1982b, p 210).

Critics of Gilligan's theory have pointed out that it is derived from a small, non-representative sample of women, all of whom are in some sort of crisis. While Gilligan criticized Kohlberg for studying only men and boys in the development of his theory, she repeated the error by studying only women and girls in the development of her theory. She assumed that his theory was correct for boys and men, and developed her theory for girls and women without directly comparing the two genders. Further, there is little empirical evidence in Gilligan's original work which supports her claims. She does not provide us with her method of scoring the interviews, or with any empirical data directly comparing the use of justice or care considerations in her abortion sample.

In response to some of these problems, Lyons (1982) developed a coding scheme for rating responses to an openended interview question that asks respondents to describe a situation, in which they were personally involved, when they did not know the moral or correct thing to do. Basing her work 
on Gilligan's (1977), Lyons delineated various aspects of the two moralities of justice and care, and derived a concise scheme for coding respondents' considerations of responsibilities (morality of care) and considerations of rights (morality of justice). (See Appendix A). Her scheme also allows for the examination of the construction, resolution, and evaluation of dilemmas.

Lyons (1983) empirically tested Gilligan's hypothesis of the existence of two distinct moral orientations. Unfortunately, her sample was small (36), and ranged across a large age group. Consequently, she had only two men and two women at each of nine age groups. Using her own coding scheme to rate the responses, Lyons concluded that while the men and women in her sample used both care and justice considerations in their responses, the care orientation was used predominantly by women and the justice orientation was used predominantly by men.

Gilligan and Attanucci (1988) conducted a similar investigation using Lyons' scoring procedures. The sample they used also had serious problems. They combined three smaller studies to arrive at a participant pool of 46 men and 34 women. The participants in the smaller studies differed considerably in background variables such as social class and age, and ethnicity. One group was drawn from a sample of professionals, the second from first-year medical students at Northeastern universities, and the third from a coeducational 
private school in the Midwest. Their study found that the majority of women and men used both care and justice considerations, but women tended to present a care focus and men a justice focus. A care or justice focus was defined by the use of one consideration at least $75 \%$ of the time in addressing a dilemma.

The above two studies appear to provide support for gender differences in moral orientation, but their small sample sizes and wide age differentials have been questioned. Vasudev (1988) has pointed out that the moral dilemmas generated by the respondents represent a wide variety of moral issues, and that an individual's use of either a justice or care perspective is susceptible to the interviewer's cues throughout the interview.

The wide variety of dilemmas generated in the Lyons procedure is indeed a serious problem. While there is validity to Gilligan's claim that a hypothetical dilemma about an unknown other is a poor representation for a real-life choice, it is also necessary to consider the content of the dilemmas generated. The situation an individual considers could easily affect the type of response given. Gilligan herself admitted this when she pointed out that the Kohlberg "Heinz dilemma" tends to elicit a justice response while the abortion dilemma tends to elicit a care response (1977, 1982a). Kerber (1986) has criticized Gilligan's conclusion that moral orientation is related to gender for this very reason, arguing that: 
It cannot be surprising that themes of responsibility and care emerge in women's articulation of their concerns about abortion. Gilligan alleges that the tendency to see "moral dilemmas in terms of conflicting responsibilities" (1982a, p. 105) is a distinct characteristic of women's decision making, but conflicting responsibilities ... are necessarily embedded in a decision on abortion [and] the theme of care is equally present ... The conclusions that Gilligan reports are implicit in the central question of the project itself (p. 304 ).

Support for the need to consider the content of the dilemma can be found in a study by Bebeau and Brabeck (1987). They presented women and men dental students with four dramas based on an earlier study of "recurrent ethical problems in the practice of dentistry", and examined gender differences in the ethical sensitivity and moral reasoning of the respondents. They found no gender differences in moral reasoning, and principles of care and justice were used equally by women and men in their reasoning about a moral ideal. They also found that women were more likely to identify the ethical issues of a dilemma, that women attended to more patient characteristics and professional responsibilities, but did not attend differentially to issues of care. Women who were at the same educational level as their male counterparts did not give greater priority to issues of care. This study highlights the importance of using the same dilemmas when 
comparing the responses of men and women. If different situations or aspects of situations are being used, it is difficult to compare responses.

Rothbart, Hanley, and Albert (1986) examined the responses of 50 college students ( 25 women and 25 men) to an open-ended personal dilemma defined and described by the participant, the Kohlberg "Heinz dilemma", that deals with whether a man should steal medicine he cannot afford to save his wife's life, and an interpersonal dilemma dealing with the "issue of how a person makes decisions in matters of physical intimacy" ( $\mathrm{p}$. 648). They found that the moral orientations of both care and justice were widely used by both women and men. In fact, no one in their study used only one type of orientation. Responses were coded with a slightly modified version of Lyons' (1983) coding scheme. It was found that the Heinz dilemma elicited primarily justice responses from $76 \%$ of the participants; the interpersonal dilemma elicited primarily care responses from $78 \%$ of the participants; and the personal dilemma elicited primarily justice responses from $40 \%$ of the participants and primarily care responses from $56 \%$ of the participants; the remaining $4 \%$ of the participants did not show a clear preference for either care or justice considerations in response to the personal dilemma. When an overall analysis of variance was done, significant main effects were found only for the type of dilemma and not for the gender of the respondent, with no significant interaction 
effect.

Pratt, Golding, Hunter and Sampson (1988) provide further support for the hypothesis that dilemma content, not gender, is the mediating factor in the use of care or justice responses. They interviewed adults and analyzed responses to both Kohlberg's hypothetical dilemmas and to a personal dilemma generated by the respondent. They found no overall stage difference in men and women in response to the Kohlberg dilemmas, and gender differences in use of care and justice only for adults between the ages of 30 and 45. Additionally, no differences in use of care or justice considerations in the personal dilemma were found when the content of the dilemma was controlled. They classified the personal dilemmas as relational or non-relational, and found that all of the non-relational dilemmas elicited justice responses and that there were no gender differences in the relational dilemmas. The studies cited above all provide evidence contrary to the conclusions of Gilligan and Lyons, and suggest that there are no essential gender differences in moral reasoning. Any differences found in the analysis of responses to dilemmas appear to depend upon the content of the dilemma rather than on the gender of the respondent.

Other mediating factors in moral responses may be the degree of difficulty the individual has in resolving the dilemma, and the importance of the dilemma. Ford and Lowery (1986) had 101 undergraduate women and 101 undergraduate men 
describe three moral conflicts that they had personally experienced. Respondents were then asked to rate, on 7-point Likert scales, both the difficulty they had in resolving the conflict and the importance of the conflict to their lives at the time of its occurrence. Additionally, the participants were given a brief description of a care and a justice orientation and asked to rate, again on 7-point Likert scales, the degree to which each orientation was a part of their own thinking about each of the conflicts they described. Reliability coefficients calculated across dilemmas showed that men were more consistent in their use of a justice orientation than women, and that women were more consistent in their use of a care orientation than men. However, women consistently rated their dilemmas as more difficult and more important than men. When the effects of difficulty and importance were used as covariates, a multiple analysis of covariance (MANCOVA) found no significant gender differences in use of justice or care ratings. Additionally, a content analysis of the dilemmas showed that the contents of men's and women's dilemmas did not significantly differ in the extent to which they were embedded in contexts of care and justice. Ford and Lowery further point out that in order to "sort out the influence of the content of the dilemmas, and concentrate on the issue of identification of subject care or justice issues, it would seem necessary to present standardized dilemmas that are equated or balanced for the extent to which 
the content is embedded in justice or care contexts" (p. 782). Friedman, Robinson, and Friedman (1987) also demonstrated that there are no reliable gender differences in the types of moral reasoning used by a sample of undergraduate women and men. They presented 47 men and 54 women undergraduates with three of Kohlberg's dilemmas and one dilemma adapted to match the Kohlberg dilemma model. After reading each dilemma, the participants were asked to rate, on 5-point Likert scales, the relative importance of six justice and six care items in their considerations. Additionally, the participants were asked to rank order the four most important of the twelve items. Each of the items had been previously validated with a separate sample as representing a care or justice perspective. Both women and men rated their use of justice considerations as slightly higher than their use of care considerations, but no significant gender differences were found. Additionally, men's and women's ratings of the relative importance of the twelve items were highly correlated, with coefficients ranging from .92 to .97 for the five points on the Likert scales.

The research cited above suggests that the use of a care or justice orientation in moral reasoning is not differentially related to gender. More important is the type of dilemma being considered and, possibly, the relative perceived difficulty and importance of the dilemma. The relation between dilemma and moral orientation seems to hold 
for both abstract hypothetical dilemmas and more personal real-life dilemmas. Previous research also suggests the importance of holding constant the type of dilemma being considered, and returning to a standardized format as opposed to the open-ended personal interview format preferred by Gilligan and her colleagues. Gilligan's work, however, has highlighted the need for realistic dilemmas to which respondents can personally relate. Research is needed with samples of a wide age range, using varied dilemmas and reliable scoring methods.

The present study was designed to meet these requirements and to further investigate the effects of gender and dilemma content on moral reasoning. Women and men participants were presented with a standard dilemma dealing with either a contemplated abortion or drug use involving their hypothetical teenage daughter or son. Participants were asked to answer open-ended questions and then to answer questions on Likert type scales which assessed the use of care or justice considerations. The open-ended dilemma was coded according to a modified version of a coding scheme developed by Lyons (1982), and the participants' essays were classified as either "care" or "justice" focused, or "care/justice" focused. The Likert type scale scores were summed to provide each person with a "care" and a "justice" score. Chi Square analysis and ANOVAs were used to analyze the data.

It was hypothesized that if the content of the dilemma 
was controlled for, there would be no significant gender differences in the moral reasoning of the respondents. Specifically, it was predicted that: (1) Women and men would not differ in their use of care or justice orientations in their open-ended discussions of either dilemma, and that (2) women and men would not differ in the relative importance they place on specific care and justice items for either dilemma; It was also hypothesized that care or justice considerations would be related to the content of the dilemma, regardless of respondent gender, and it was predicted that (3) a dilemma dealing with abortion would elicit more care orientations and responses from both men and women than a dilemma dealing with cocaine use, and that a cocaine use dilemma would elicit more justice orientation responses than an abortion dilemma. Finally, due to stereotypes in our society about the nature of boys and girls, it was predicted that dilemmas with a girl as the protagonist would elicit more care orientations and responses, and dilemmas with a boy as the protagonist would elicit more justice orientations and responses.

Method

\section{Participants}

Participants were 127 women and 63 men volunteers, ranging in age from 17 to 64, with a mean age of 25.4. As can be seen in Table 1 , seventy-eight participants (52 women and 26 men) were adult students attending classes at the College of Continuing Education, (mean age $=34.3$ ) whose participation 
made them eligible for a $\$ 30.00$ drawing for dinner at a local restaurant. A larger group of 50 men and 89 women had signed consent forms and took home the materials, along with an addressed and stamped envelope, but only 78 usable packets were returned (a response rate of 56 percent).

One hundred twelve participants ( 75 women and 37 men) were students attending an introductory psychology class at the University's main campus (mean age $=19.3$ ). These students received extra course credit for their participation. Participation of all respondents was completely voluntary, and participants were told that they could withdraw at any time.

Table 1

Participants' Mean Ages and Gender

\begin{tabular}{llcc}
\hline & CCE & Intro Psyc & Total \\
Number of Women & 52 & 75 & 127 \\
Mean Age of Women & 35.8 & 18.8 & 25.4 \\
Number of Men & 26 & 37 & 63 \\
Mean Age of Men & 31.2 & 20.3 & 24.8 \\
Total \# Participants & & & 190 \\
Mean Age of Sample & 78 & 112 & 25.4 \\
\hline
\end{tabular}


The participants were predominantly heterosexual (98\%), Euro-American (96\%), and of a middle-class background. Fiftynine percent identified themselves as Catholic, $9 \%$ as Protestant, $8 \%$ as Jewish, and $25 \%$ as another or no religion. Among the sample, 77\% had never been married, 17\% were married at the time of the study, and $5 \%$ were divorced; $86 \%$ had no children.

\section{Procedure}

Originally, the Continuing Education students were meant to be one sample, and the Introductory Psychology students a replication, with some slight differences in the instructions. Because these differences had no impact on the outcome (i.e., the dependent measures), the two samples have been combined.

All interested students signed informed consent forms advising them that they would be asked to read and write about a sensitive and controversial dilemma, that their responses would be completely confidential, that their participation was voluntary, and that they could decide not to continue participating at any time. They were also given an opportunity to enclose their address on the consent form so the investigator could mail them a description of the study's findings.

After signing the informed consent, participants received 
one of four questionnaire packets containing: a demographic questionnaire; a hypothetical dilemma dealing with either drug use or abortion; open-ended questions dealing with responses to the dilemma; and questions to be answered on Likert scales. Four dilemmas were randomly distributed: an abortion or cocaine use involving either a son or a daughter. The respondents were asked whether they had ever been in a situation similar to the one described; and finally they were asked to rate on a likert scale of 1 to 5 the ease they had imagining themselves in the dilemma described. The participants were asked to spend approximately 30 to 45 minutes filling out the questionnaires in a quiet and private place and then to return them to the investigator either by mail (Continuing Education students) or in person (Introductory Psychology students).

Stimulus Materials

Instructions given to the Continuing Education students were as follows:

People often confront dilemmas. A dilemma is a situation where you have many options and are unsure of the correct thing to do; some dilemmas are trivial and some are more significant. For example, if you see a classmate cheating on an exam, you may not be sure how to react. Please read the following scenario and pretend that you are in the situation described, then write what you would do in that situation and why. In your answer, please 
describe the dilemma as you see it, how you will try to resolve the dilemma, and what you think will happen after your proposed resolution of the dilemma.

One of the following four scenarios followed the instructions. 1. Your sixteen year old son has been dating a young woman for some time. She becomes pregnant and is contemplating an abortion. Your son asks you for advice and help.

2. Your sixteen year old daughter has been dating a young man for some time. She becomes pregnant and is contemplating an abortion. Your daughter asks you for advice and help.

3. You discover that your sixteen year old son has been using cocaine. You are contemplating whether or not to turn him over to the police.

4. You discover that your sixteen year old daughter has been using cocaine. You are contemplating whether or not to turn her over to the police.

For Introductory Psychology students, the definition of a dilemma and the example of cheating were presented as described above, but instead of asking participants to describe what they would do and why, and then listing what that answer would entail, the following specific questions were asked after the dilemma was presented:

Would this be a dilemma for you? If so, please describe what the dilemma would be. What issues would you consider in making a decision? What would you do and why? (I am most interested in your thinking and your reasons, not 
only in what you would do). How would you decide if you had made the right decision?

After each question was space for the respondents to answer.

\section{Response Measures}

The main ideas of all the essays were coded as either care or justice by a trained undergraduate rater according to a modified version of a coding scheme developed by Lyons (1983), (Appendix A). Those essays where either a justice or a care consideration was used more than $75 \%$ of the time were categorized as either "justice" or "care-focused". Other essays were categorized as "both".

Respondents were asked, following the presentation of the dilemma, "how important were the following items in your consideration of the dilemma?" For each of eight items, a 5point Likert scale was presented. This method was adapted from Friedman, Robinson, \& Friedman (1987). A rating of 1 indicated little or no importance, 3 indicated moderate importance, and 5 indicated high importance. Four of the items address care considerations ( $C$ items) and four address justice considerations ( $J$ items). Responses to the 4 care and the 4 justice items were summed to give each respondent a numerical "care" and "justice" score. The items are as follows:

1 (C). Consideration of the actual consequences for the people involved.

2 (C). Consideration of the effects on my relationship with my child. 
3 (C). Consideration of the particular situation and the characters of the all the people involved.

(C). Consideration of the obligation to avoid hurting the people involved.

5 (J). Consideration of whether or not there is a moral principle at stake.

6 (J). Consideration that certain human rights are more fundamental than the law.

7 (J). Consideration of the rights of all the people involved.

8 (J). Consideration of the right of each individual to make an independent value decision.

\section{Other Measures}

The final page of the packet asked participants whether they had ever been personally involved in a situation similar to the one described, and if so to explain the circumstances briefly. The participants were also asked to rate on a scale of 1 to 5 how easy it was to imagine themselves in the situation described (1=very easy, $3=$ moderately difficult, and $5=$ extremely difficult) .

\section{Results}

No significant differences between the Continuing Education and Introductory Psychology participants were found on any measure, except for Ease of Imagination: Continuing Education Mean $=2.62$, Introductory Psychology Mean $=3.22$, $\underline{p}<.01$, so their data were analyzed together. Open-Ended Questionnaire Analysis 
Responses to the-open ended questionnaire were coded by a trained undergraduate rater who was unaware of the hypotheses and the gender of each respondent. Each main idea within the respondent's essay was categorized as either "justice" or "care", according to a modified version of the coding scheme developed by Lyons (1983). The number of considerations in each category was then added, and divided by the total number of considerations. Those who used either care or justice considerations for more than $75 \%$ of their considerations were classified as "Care" or "Justice" ; those who used neither care nor justice for $75 \%$ of the total number of considerations were classified as "Care/Justice".

In order to determine reliability, 10 percent of the questionnaires were also coded by the investigator, blind to the gender of the respondent. The calculated percent agreement for those 20 essays was $70 \%$.

Chi Square analyses were performed to test the relationships between the frequency of persons categorized as "Care", "Justice" or "Care/Justice" and (1) gender of the respondent, (2) the dilemma responded to, and (3) gender of the protagonist in the dilemma.

As seen from the data presented in Table 2, gender was not a significant variable. There were no statistically significant differences between the observed and expected frequencies for men and women. The majority of women's and men's essays were classified as Care/Justice (56.9\% and 63.3\%, 
respectively); Categorized as primarily care in orientation were $34.1 \%$ of the women's essays and $25.0 \%$ of the men's essays. Categorized as primarily justice in orientation were 8.9\% of the women's essays and $11.7 \%$ of the men's essays.

Table 2

Observed and Expected Frequencies of Care, Justice, and Care/Justice Responses by Women and Men

Gender

Type of Response

Men

Women

CARE

observed

15

42

(expected)

(18.7)

$(38.3)$

JUSTICE

observed

7

11

(expected)

(5.9)

(12.1)

CARE/JUSTICE

observed

(expected)

Chi Square $=1.669 ; \mathrm{df}=2 ; \underline{p}>.05$

As can be seen in the data shown in Table 3 , the content of the dilemma proved to be a significant variable, in a direction opposite to that predicted. The abortion dilemma elicited more justice and fewer care responses than expected, 
and the drug dilemma elicited more care responses and fewer justice responses than expected. The majority of essays were classified as Care/Justice (58.7\%). Categorized as care were $22.0 \%$ of the essay responses to the abortion dilemma and $42.2 \%$ of the essay responses to the drug dilemma. Categorized as justice were $13.0 \%$ of the essay responses to the abortion dilemma and 6.0 \% of the essay responses to the drug dilemma.

Table 3

Observed and Expected Frequencies of Care, Justice, and Care/Justice Responses to a Dilemma Dealing With Abortion or Drug Use

\section{Dilemma}

Type of Response

Abortion

Drug

\section{CARE}

observed

(expected)

JUSTICE

observed

(expected)

CARE/JUSTICE

observed

(expected)

Chi Square $=9.505 ;$ df $=2 ; \mathrm{p}<.01$. 
Gender of the protagonist was not a significant variable, as can be seen from the data in Table 4. There were no significant differences between observed and expected frequencies of care, justice, or care/justice categories related to whether a daughter or son was the protagonist. Table 4

Observed and Expected Frequencies of Care, Justice, and Care/Justice Responses for Dilemmas Involving Daughters or Sons

Gender

Type of Response

Daughters

Sons

$\underline{\text { CARE }}$

observed

27 30

(expected)

(28.7)

JUSTICE

observed

9

9

(expected)

CARE/JUSTICE observed

(expected)

Chi Square $=.301 ; \mathrm{df}=2 ; \mathrm{p}>.05$

Likert Scale Analysis

Responses to the Likert scale items were summed to give each person a "Care" score and a "Justice" score. These scores 
were analyzed by two separate $2 \times 2 \times 2$ ANOVAs using gender of participant, dilemma content, and gender of protagonist as independent variables, and scores on each type of response as dependent variables. Scores could range from a low of 4 to a high of 20 .

For the Care scores, no significant main effects or interactions were obtained. The Means and Standard Deviations are presented in Table 5.

Table 5

Women's and Men's Mean Care Scores for an Abortion and Drug Dilemma Involving Daughters or Sons

\begin{tabular}{|c|c|c|c|c|c|}
\hline \multicolumn{2}{|c|}{ Respondent } & \multicolumn{2}{|c|}{ Dilemma } & \multicolumn{2}{|c|}{ Protagonist } \\
\hline Women & Men & Abortion & Drug & Daughters & Sons \\
\hline 15.83 & 16.30 & 15.66 & 16.40 & 15.71 & 16.88 \\
\hline 3.12 & 2.45 & 2.75 & 3.08 & 3.07 & 2.76 \\
\hline
\end{tabular}

For the Justice scores, there was a significant main effect for dilemma content $\underline{F}(1,182)=9.200,(p<.01)$. The Means and Standard Deviations are presented in Table 6 . No other main effects or interactions were significant. 
Table 6

Women's and Men's Mean Justice Scores for an Abortion and Drug Dilemma Involving Daughters or Sons

\begin{tabular}{|c|c|c|c|c|c|}
\hline \multicolumn{2}{|c|}{ Respondent } & \multicolumn{2}{|c|}{ Dilemma } & \multicolumn{2}{|c|}{ Protagonist } \\
\hline Women & Men & $\overline{\text { Abortion }}$ & Drug & Daughters & Sons \\
\hline 14.26 & 13.89 & $* 14.85$ & 13.26 & 14.17 & 14.11 \\
\hline 3.49 & 3.96 & 3.13 & 4.03 & 3.61 & 3.70 \\
\hline
\end{tabular}

Additional Analysis

An additional $2 \times 1 \times 2 \times 2$ ANOVA was performed which investigated whether any of the independent variables (gender of participant, dilemma content, gender of protagonist) varied significantly with respect to the ease respondents had in imagining themselves in the situation described. There were no significant main effects or interactions.

Responses to the question "have you ever been personally involved in a situation similar to that described?" varied considerably. Some individuals reported being influenced by the experiences of friends or family, by their religious background, or by personal experience. Due to the wide variety of responses, and differing interpretations of what personal involvement meant, no statistical analyses were conducted for this item. 


\section{Discussion}

The purpose of this study was to assess the use of care and justice considerations in response to standardized, but personal, dilemmas. Use of care and justice orientations were assessed in two ways. Responses to an open-ended dilemma were categorically coded, and care and justice scores were derived from responses to Likert scale items.

The dilemmas used were a compromise between the traditional "hypothetical dilemma" and dilemmas provided by respondents. It was felt that use of a standardized dilemma was important, but that it had to be one in which the participants could become involved and picture themselves. The use of written responses instead of face-to-face interviews allowed the responses to be free from unintentional cues provided by the interviewer. While some of the richness of individual responses may have been lost, it was felt that concrete, written responses, free from cuing, would provide the cleanest sample of the person's preferred mode of response.

On the basis of both the categorical and continuous measures, the content of the dilemma being considered was found to be a major variable in the use of care or justice moral considerations. The dilemma dealing with abortion elicited more "Justice" essays and fewer "Care" essays than expected by chance, and respondents reported that the justice considerations weighed more heavily in their consideration of 
the abortion dilemma than the drug dilemma. The dilemma dealing with drug use elicited more "Care" and fewer "Justice" essays than expected by chance.

While these results support the hypothesis that the content of the dilemma is important in determining the use of care and justice responses, they are opposite in direction to the original prediction. It was predicted that the drug dilemma would elicit more justice concerns, and the abortion dilemma more care concerns. That the opposite was found in this particular sample of respondents may well be due to the high number of Catholic participants in the study. Many who responded to that dilemma said that abortion is morally wrong, a judgment classified as justice. Often these respondents expressed beliefs that the contextual factors were secondary to the morality of abortion, and that regardless of what their child wanted to do, they, as parents, would not permit an abortion. Additionally, often those who were in favor of abortion as a choice still approached the essay with a justice perspective. They discussed the importance of choice and legalized abortion and not the specific context of the dilemma.

Feelings about the morality of abortion were expressed clearly even among a young college sample, who might be expected to be the most liberal in their views. Interestingly, these results differ from those of Gilligan and Belenky (1980) where the topic of abortion triggered Care responses. In that 
work, the women were contemplating abortion for themselves, while in the present study, the abortion was for a hypothetical teenager. Perhaps when an individual is personally involved in a situation her or his reasoning differs from when he or she contemplates a hypothetical dilemma.

The present results relevant to an abortion dilemma are particularly interesting in comparison to the responses to the drug dilemma. Cocaine use is clearly harmful and illegal, yet respondents were much more likely to take situational variables such as the age of the teenager, previous drug use, and the teenager's "personality" into account before making a decision. Such considerations may reflect the situations of the respondents. Drug use on a college campus is fairly common, and may not seem as problematic or as much a moral issue as an unwanted pregnancy.

No gender differences in the use of care and justice considerations were found, as predicted. This result contrasts with Gilligan's and others' proposition that women are more likely to use "Care" and men are more likely to use "Justice". In fact, for both women and men, the most likely choice was a blend of both care and justice considerations (55.3\% of all essays were classified as Care/Justice). Additionally, the mean care scores were higher for men, while the mean justice scores were higher for women. While the differences were not significant, the direction of the means further questions 
Gilligan's proposition. Neither gender was more likely than the other to use a particular form of consideration in dealing with either the abortion or drug dilemma.

There were no significant differences between women and men participants in the relative ease they had in imagining themselves in the situation presented to them. Most participants found imagining themselves in the scene to be "moderately easy". It is significant to note that while the majority of respondents were not married (77\%) and did not have children (86\%), they still reported not having much difficulty imagining themselves in the situation described. Perhaps this is due to the participants being on a college campus, where both drug use and abortion are not uncommon. This finding lends further support to the idea that an individual's background and the content of the dilemma are significant factors in the individual's response to that dilemma.

There were also no differences in the use of care and justice orientations and responses when the dilemma involved a daughter or a son. It had been expected that dilemmas involving a hypothetical daughter would evoke more care responses than one involving a son; however, the gender of the protagonist was not a significant variable.

It is of interest to note that a "Care focused" response was more common than a "Justice focused" response for all of the dilemmas; $29.5 \%$ of all essays were classified as "Care 
focused" as compared with only $9.5 \%$ classified as "Justice focused". It is likely that care values were triggered because respondents were asked to imagine themselves in the situation, and because the dilemmas concerned a hypothetical teenaged child. In such dilemmas, it is likely that caring, responsibility, and attempts to understand the context of the situation would take priority over specific moral rules, obligations, rights, and absolute principles. However, it is crucial to keep in mind that the vast majority of respondents used both care and justice considerations when evaluating each of the moral dilemmas utilized in this study.

One of the drawbacks of the present study is the participants were all relatively young college students. While some diversity in age was achieved via the Continuing Education students, it is important to replicate this study with a truly random sample of the population. Additionally, many of the participants were not parents; because of their minority, I was unable to compare the responses of those who did and did not have children. It is possible that a respondents' views about a hypothetical situation involving a teenaged child would change once that person had children. Conclusions

The results of this study support the hypothesis that the content of the dilemma being considered is important in influencing the responses to it. Additionally, they highlight the fact that the gender of the participant is not related to 
the preferred mode of response.

The results further suggest that an individual's background and upbringing will influence her or his use of care or justice considerations. For example, fundamental beliefs in the morality or immorality of abortion appeared to outweigh the effects of gender. It is reasonable to assume that the content of the dilemma under consideration interacts with individual's personal experiences, attitudes, and beliefs, and influences her or his reasoning about the dilemma.

Future research should investigate other dilemmas and contexts which might more clearly elicit care and justice orientations. Additionally, researchers should examine factors other than gender of the participant. Factors suggested by the present study are religion and ethnicity, or the extent to which a particular dilemma taps certain moral principles judged by the respondent to be unassailable and constant. It is essential to pay attention to the situational cues the dilemma provides to the respondents. Additionally, it would be worthwhile to compare an individual's preferred mode of response to other attitudinal and belief measures which might be related to the content of the dilemma being considered.

It is also important to consider that people may approach a moral dilemma from a perspective other than care or justice. For example, people may conduct a cost benefit analysis of the situation in order to aid their decision making. Another 
possibility is consideration of utility; in other words, an individual might do whatever would be most beneficial to the largest group of people, or whatever serves her or his own self interests. Yet another possibility is an emotional response - a response based on whatever "feels right" at that given moment. Certainly some people act on "instinct" or on a gut reaction in at least some situations.

What is important to recognize is that any dichotomy considers only two possible perspectives, in this case, care versus justice. There are certainly other realms of moral reasoning which should be considered. Exploratory research should be done to look for other approaches to moral dilemmas, both in response to hypothetical and participant-generated situations.

While there were no gender differences in preferred mode of moral reasoning, there are very real gender differences in the allocation of resources and power in our society. It would be useful for researchers to shift their focus from the gender of the respondent to other situational variables such as power, resources and income. Perhaps those individuals with more power in a given situation are more inclined to use justice considerations than care considerations, while those with less power would be more inclined to use care considerations. It would make sense that a relatively powerless individual would need to be more in tune with the contextual cues of a situation; that person may need to pay 
attention to individual circumstances and the costs and benefits of a situation rather than to any specific moral principles.

The line of research represented by this study is particularly important because it questions assumptions about the ways in which people think and behave. From a very early age members of this society are taught that women are "care oriented" and men are "justice oriented". Because we are taught to view the world through a gendered lens, we often see only what we expect to see. That is, when we view men or women acting in ways inconsistent with our perspective, that information tends to be forgotten or lost. Too often the "fact" that women are more caring and nurturing than men is used as a justification for denying women access to high paying and high powered jobs. Similarly, men are often excluded from child-rearing and caretaking because "it's not in their nature". Empirical research should question and test our assumptions about human behavior, particularly when the consequences of our assumptions and stereotypes are so devastating. 


\section{Appendix A}

Morality as Care and Morality as Justice: A Scheme for Coding Considerations of Response and Considerations of Rights

I The construction of the Problem

A. Considerations of Response (Care)

1. General effects to others (unelaborated)

2. Maintenance or restoration of relationships; or response to another considering interdependence

3. Welfare/well-being of another or the avoidance of conflict; or, the alleviation of another's burden/hurt/suffering (physical or psychological)

4. Considers the "situation vs./over the principle"

5. Considers care of self; care of self vs. care of others

B. Considerations of Rights (Justice)

1. General effects to the self (unelaborated including "trouble" "how decides")

2. Obligations, duty or commitments

3. Standards, rules or principles for self or society; or considers fairness, that is, how one would like to be treated if in other's place

4. Considers the "principle vs./over the situation"

5. Considers that others have their own contexts

II. The Resolution of the Problem/Conflict [same as part I] 
III. The Evaluation of the Resolution

A. Considerations of Response (Care)

1. What happened/how worked out

2. Whether relationships maintained/restored

B. Consideration of Rights (Justice)

1. How decided/thought about/justified

2. Whether values/standards/principles maintained 


\section{Bibliography}

Baumrind, D. (1986). Sex differences in moral reasoning: response to Walker's (1984) conclusion that there are none. Child Development, 57, 511-521.

Bebeau, M. J. \& Brabeck, M. M. (1987). Integrating care and justice issues in professional moral education: a gender perspective. Journal of Moral Education, 16, 189-203.

Colby, A. \& Kohlberg, L. (1987). The measurement of moral judgment (vol 1). Cambridge, MA. Cambridge University Press.

Ford, M. R. \& Lowery, C. R. (1986). Gender differences in moral reasoning: a comparison of the use of justice and care orientations. Journal of Personality and Social Psychology, 50, 777-783.

Friedman, W. J., Robinson, A. B. \& Friedman, B. L. (1987). Sex differences in moral judgments? a test of Gilligan's theory. Psychology of Women Quarterly, 11, 37-46.

Gilligan, C. (1977). In a different voice: women's conceptions of self and of morality. Harvard Educational Review, 47, 481-517.

Gilligan, C. (1982a). In a different voice: psychological theory and women's development. Cambridge, MA: Harvard University Press.

Gilligan, C. (1982b). New maps of development: new visions of maturity. American Journal of Orthopsychiatry, 52, 199212 . 
Gilligan, C. \& Attanucci, J. (1988). Two moral orientations: gender differences and similarities. Merrill-Palmer Quarterly, 34, 223-237.

Gilligan, C. \& Belenky, M. F. (1980). A naturalistic study of abortion decisions. In R. Selman and R. Yando (Eds.) Clinical-Developmental Psychology. New directions for Child Development, no. 7. San Francisco, CA: Jossey-Bass Inc.

Kerber, L. K. (1986). On In a Different Voice: an interdisciplinary forum. Some cautionary words for historians. Signs, 11, 304-310.

Kohlberg, L. (1971). From is to ought: how to commit the naturalistic fallacy and get away with it in the study of moral development. In T. Mischel (Ed.), Cognitive development and epistemology. New York: Academic Press. Lyons, N. P. (1982). Conceptions of self and morality and modes of moral choice: Identifying justice and care in judgements of actual moral dilemmas. Unpublished Doctoral Dissertation, Harvard University, MA.

Lyons, N. P. (1983). Two perspectives: on self, relationships, and morality. Harvard Educational Review, 53, 125-145. Pratt, M. W., Golding, G., Hunter, W. \& Sampson, R. (1988). Sex differences in adult moral orientations. Journal of Personality, 56, 374-391.

Rothbart, M. K., Hanley, D. \& Albert, M. (1986). Gender differences in moral reasoning. Sex Roles, 15, 645-653. 
Walker, L. J. (1984). Sex differences in the development of moral reasoning: a critical review. Child Development, 55, 677-691.

Walker, L. J. (1986). Sex differences in the development of moral reasoning: a rejoinder to Baumrind. child Development, 57, 522-526.

Vasudev, J. (1988). Sex differences in morality and moral orientation: a discussion of the Gilligan and Attanucci study. Merrill-Palmer Quarterly, 34, 239-244. 